\title{
Correction to: Jodocus Trutfetter (c. 1460-1519) on Internal Senses
}

\author{
Pekka Kärkkäinen
}

\section{Correction to:}

Chapter 5 in: S. N. Mousavian, J. L. Fink (eds.), The Internal Senses in the Aristotelian Tradition, Studies in the History of Philosophy of Mind 22, https://doi.org/10.1007/978-3-030-33408-6_5

Owing to an oversight "Abstract" is incorrect in the previous online version of chapter 5. This has now been corrected as below.

"Jodocus Trutfetter's presentation of the internal senses is firmly rooted in his via moderna - type semantic approach to faculty psychology. This is evident already in the 1514 version of his natural philosophy, but it is reinforced in the abriged revision from 1517. It may seem that in 1514 Trutfetter hides his own position in the central question behind the presentation of different views, but in the later edition he focuses on presenting one most plausible view. Regarding the use of Thomist terminology, the earlier edition would suggest a broader adoption of Thomist views, but this may be due to its way of presenting the various positions more extensively. The latter edition continues and even reflects more clearly Trutfetter's general attitudes towards various authorities, where he defended the use of the authorities of the via moderna, but did not exclude the earlier authorities either. Among them Aquinas and the Thomist position continued to have a specific value for him."

The updated online version of this chapter can be found at https://doi.org/10.1007/978-3-030-33408-6_5 